\title{
Numerical Investigation of Cold Thermal Energy Storage Using Phase Change Material in Freezer
}

\author{
Omid Ghahramani Zarajabad, Rouhollah Ahmadi, and Saeed Ghaffari
}

\begin{abstract}
Freezer is one of the electrical components that can be found in any building. Like any electrical appliance domestic freezer consumes a significant amount of energy during its working time. During recent decades a lot of solutions have been found to reduce this energy consumption. One of the most usable and appropriate ones is implementation of phase change material (PCM) in a Cold Thermal Energy Storage (CTES) system which can be installed in a household freezer. In this paper numerical investigation of using CTES system in a domestic freezer in order to diminish energy consumption during pick hours (18-22:30), is studied. Regard to the temperature ranges of the freezer, $\mathrm{NaCl}-\mathrm{H}_{2} \mathrm{O}$ is used as a PCM in the CTES system. In a distinct period of time, a large amount of cold thermal energy in latent heat form is stored at low temperature in the PCM, and it is released in the freezer's cabin when the compressor is off. Accordingly, numerical modeling and simulation using Computational Fluid Dynamics (CFD) software on charging and discharging cycle of PCM are done to measure cold storage period and amount of saved energy. The results reveal that using CTES could keep the freezer in the standard thermal condition without using a compressor, for 4.5 hours. These results show that if the PCM used in CTES system for a year, it could reduce energy, fossil fuel consumption and $\mathrm{CO}_{2}$ emission up to $45.7 \mathrm{kWh}, 13.7$ liters and $32.0 \mathrm{~kg}$, respectively.
\end{abstract}

Index Terms-Cold thermal energy storage; Phase change material; Energy saving; Environmental effect

\section{INTRODUCTION}

The cooling systems are one of the necessary devices which are found in any building or industry. Using cold thermal energy storage (CTES) would help refrigeration to reserve the cold energy for later usage. They are designed to store the lower temperature in comparison with the ambient temperature [1]. The energy is usually stored and released in the specific cycles in order to prepare suitable condition for the thermal system [2]. It is important to know that reserving cold energy in the thermal mode is so appropriate than storing electric power to supply cooling load in any urgent time [3]. Storing energy and supplying it in the urgent time will abate not only energy consumption but also $\mathrm{CO}_{2}$ emission. Also using CTES system is the proper solution to diminish energy cost during pick time. Based on the report of the California Energy Commission [4], if there were a

Published on September 6, 2017.

Omid Ghahramani Zarajabad is with the School of New Technologies, Iran University of Science and Technology, Tehran, I.R. Iran (e-mail: o_ghahramani@alumni.iust.ac.ir).

Rouhollah Ahmadi is the corresponding writer and he is the assistant professor of the School of New Technologies, Iran University of Science and Technology, Tehran, I.R. Iran (e-mail: ahmadi@iust.ac.ir).

Saeed Ghaffari is with the Mechanical Engineering department, Mazandaran University of Science and Technology, Babol, I.R. Iran (email: saeedghafari2294@gmail.com). technology to produce off-peak electricity, it would make the system so profitable. Many applications of cold thermal energy storage systems have been employed in the industry. Many of those techniques have focused on different technologies and strategies to store the cold energy for building applications using thermal reservoirs or pre-cooling control systems [5]. Another well-known application of CTES systems is the preservation and shipment of temperature sensitive materials [6], [7]. There are some key methods to store cold thermal energy and one of the most common and useful ones is using phase change material (PCM). PCMs can store cold thermal energy based on their latent heat capacity and release it to the desired system. In the following, first some important research in the field of CTES will be discussed and finally, the CTES mechanism and the most suitable PCMs for using in the CTES system will be introduced.

In the case of using PCM and CTES system, Mastani [8] studied the application of PCMs in domestic refrigerators experimentally based on their modeling approaches. Moreover, advantages and disadvantages of each type of storage were presented and they investigated the potential and profits of PCMs for installing in the household refrigerators. In 2014, Real [9] surveyed using CTES system in the heating, ventilation and air conditioning system (HVAC) to improve the heat pump performance. Marques [10] studied the position of installing PCM slabs in the refrigerator, horizontally and vertically. According to their investigation, when the CTES was installed horizontally, it could prepare cooler condition, in comparison with the vertical model. Also, to prepare cooler condition combined model would be the best choice. In 2013, Rismanchi [11] developed a computer model to determine the potential energy savings of implementing CTES systems. It was found that the overall energy used by the full load storage strategy is considerably more than the conventional system. However, applying the load leveling storage strategy caused that the overall energy usage was reduced up to $4 \%$ lower than the non-storage system. Azzouz [12], [13] carried out experimental tests to investigate the performance of a household refrigerator using a PCM. Accordingly, the CTES can keep the system in the allowed range of temperature for 9 hours and there is no need to the compressor during this period.

As it was mentioned earlier, one of the ways to increase the productivity of refrigeration system is using phase change material in the cold storage systems. Technically, cold storage systems are one of the thermal energy storage systems that can store energy in cooler temperatures in sensible and latent heat form. In sensible one, the material in the storage system stores cold thermal energy by decreasing 
the temperature and releases it by increasing the temperature. On the other hand, in the latent cold thermal energy storage system (LCTES) the most of the cold thermal energy is stored and released during the phase change of material (solidification and melting) [14]. The material used in LCTES system is known as a phase change material (PCM). The amount of cold thermal energy which is stored by PCM depends on its amount, specific heat capacity and temperature changes. In general, the benefits of sensible heat method are high thermal conductivity and low-cost materials used in cold storage [14]. Otherwise, as the latent heat method can prepare a large amount of enthalpy because of phase change process (which is 100 to 200 times larger than the sensible heat method), it would be the most proper method for energy saving phenomenon. Therefore, the energy density in LCTES system is much more than the sensible heat storage system and causes the system volume to be smaller [14].

There are two most important requirements for choosing PCMs in sub zero cold storage systems: a proper phase change temperature and a larger fusion heat. However, other factors can be deemed such as follow [15]:

First, acceptable cycling stability, which means the PCM can store and release the energy for many cycles; Second, high thermal conductivity and low super cooling. Super cooling is the phenomenon of lowering the liquid temperature below its freezing point in order to start the solidification; Third, stable chemical property, low corrosion, and low environmental pollution emission; Fourth, easy manufacturing and low cost.

In fact, there are no chance to opt the PCM which has all of those positive aspects. In order to understand the importance of the mentioned requirement above, all of them are compared for three categories of common PCMs in Fig. 1 [15]. In this figure, three positive thermal properties (thermal conductivity, latent (fusion) heat, and density) are shown above the dotted line while three negative thermal properties (corrosion, super cooling, and flammability) are shown below it. The farther the colored shape extends along a given arrow, the better the performance along that dimension. Part (1), (2), and (3) shows the radar charts for eutectic water-salt solutions, non-eutectic water-salt PCMs, and ideal common PCMs, respectively. From the comparison, it can be fathomed; although, eutectic watersalt solutions have advantages of higher thermal conductivity, latent heat and density, and lower flammability than others, but they are usually corrosive materials and have super cooling during their phase change process. Conversely, non-eutectic water-salt PCMs do not have these good characters of eutectic water-salt solutions, but they do not have serious corrosion and super cooling issues [15].
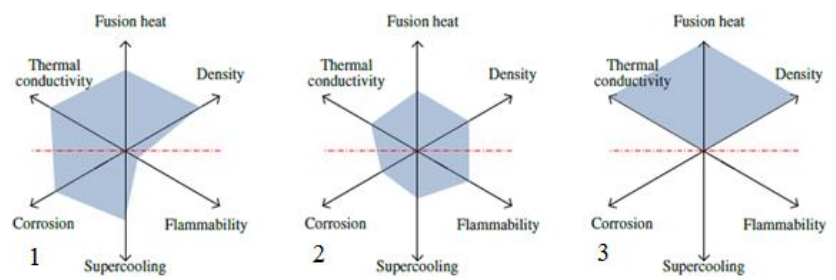

Fig. 1. Thermal properties comparison of common PCMs [15]

Regarding all available PCMs for sub-zero applications, eutectic salts are the best choice as their high latent heat capacity and proper phase change temperature range. But, the most of the research on PCMs is focused on eutectic water-salt solutions because of their high latent heat capacity and proper phase change temperature range. Indeed, when the eutectic salt added to the water, its phase change point would degrade. In this case there is an important phenomenon about the eutectic water-salt solutions' phase change. According to research eutectic salt solution may not freeze from a pure liquid state to a solid state [15]. To clarify that, the phase diagram of eutectic water-salt solutions is shown in Fig. 2. Solidification point is $0{ }^{\circ} \mathrm{C}(273 \mathrm{~K})$ when the composition is $100 \%$ water. The freezing point of the water-salt solution would diminish when a little more salt added. In this condition, only pure water freezes out of the solution and the salt remains in solution. If more salt added, the freezing point would depress further until the eutectic point (point P), the lowest freezing point on the curve, is reached [15]. At this point, both the salt and the water freeze out of the solution, and the composition of the frozen material is exactly the same as that of the solution. With more salt added, the solution's freezing temperature starts to increase and anhydrous salt precipitates out on freezing [15]. Under a particular salt concentration (point $\mathrm{P}$ ), the solution freezes and melts completely at a constant temperature (point P) while releasing and storing large amounts of energy. This kind of PCM is called as a eutectic water-salt solution [15]. In Table, I list of main applicable eutectic PCMs which can be used in sub-zero temperature range is provided. For investigating CTES system in this paper, $\mathrm{NaCl}-\mathrm{H}_{2} \mathrm{O}$ is selected as PCM, because of the operating temperature of household freezers (250 to $260 \mathrm{~K})$ [2], [12], [13], and its stability, high heat capacity, low cost and also its safety. In Table II, the chosen PCM's thermophysical properties are reported.

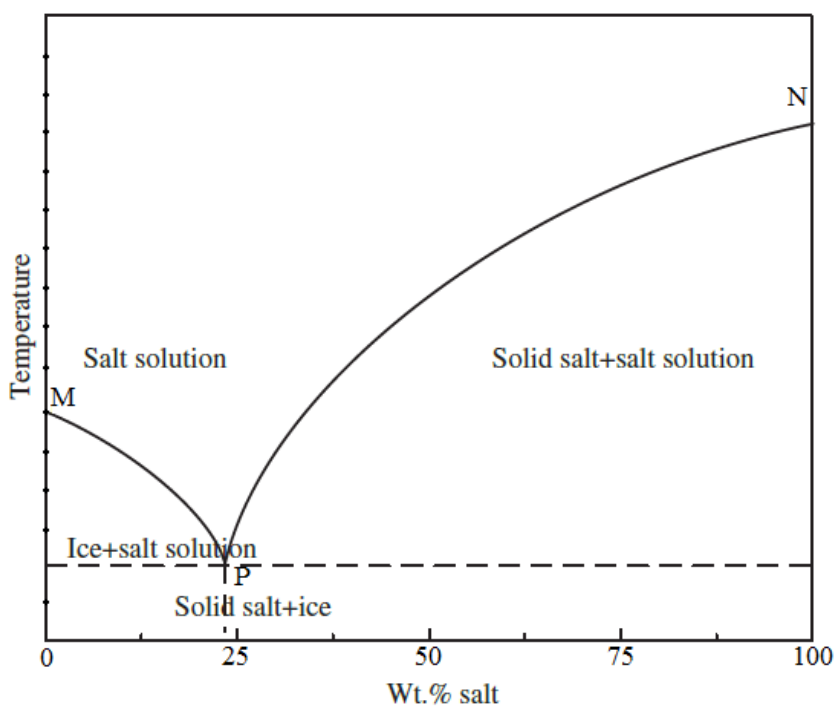

Fig. 2. Phase diagram for eutectic salt-water solutions [15]

The present study aims to evaluate the effectiveness of a cold thermal energy storage using PCM in a regular household freezer. A numerical investigation is implemented to obtain the energy consumption and refrigerator performance, quantitatively. Moreover, since the cyclic operation of the refrigerator is different when CTES 
is used, the temperature of PCM and refrigerator cabin was monitored during charging and discharging of CTES. A significant attention was paid to the effectiveness and performance role of CTES in the system. It was aimed that energy saving and environmental emissions reduction to be found during pick time mode, finally.

TABLE I: LIST OF MAIN PCMS USED IN COLD STORAGE SYSTEMS [14], [15]

\begin{tabular}{cccc}
\hline \hline \multirow{2}{*}{$\mathrm{PCM}$} & $\begin{array}{c}\mathrm{H}_{2} \mathrm{O} \\
\%\end{array}$ & $\begin{array}{c}\text { Melting Temperature } \\
(\mathrm{K})\end{array}$ & $\begin{array}{c}\text { Latent Heat } \\
(\mathrm{Kj} / \mathrm{kg})\end{array}$ \\
\hline $\mathrm{NaBr}-\mathrm{H}_{2} \mathrm{O}$ & 60 & 245 & 175.69 \\
$\mathrm{NaCl}-\mathrm{H}_{2} \mathrm{O}$ & 78 & 252 & 234 \\
$\mathrm{KNO} 3-\mathrm{H}_{2} \mathrm{O}$ & 91 & 270 & 296.02 \\
\hline \hline
\end{tabular}

TABLE II: NACL-H ${ }_{2} \mathrm{O}$ THERMODYNAMIC PROPERTIES [15]

\begin{tabular}{cccc}
\hline \hline PCM & $\begin{array}{c}\text { Density } \\
\left(\mathrm{kg} / \mathrm{m}^{3}\right)\end{array}$ & $\begin{array}{c}\text { Specific Thermal } \\
\text { Capacity }(\mathrm{KJ} / \mathrm{kg} . \mathrm{K})\end{array}$ & $\begin{array}{c}\text { Thermal } \\
\text { Conductivity } \\
(\mathrm{W} / \mathrm{m} . \mathrm{K})\end{array}$ \\
\hline $\mathrm{NaCl}-\mathrm{H}_{2} \mathrm{O}$ & 1180 & 3.34 & 0.57 \\
\hline \hline
\end{tabular}

\section{MATERIAL AND METHODS}

\section{A. Physical Model and Numerical Method}

In this study, a household freezer with dimensions of 28 $\mathrm{cm} \times 31.5 \mathrm{~cm} \times 43.5 \mathrm{~cm}$ is considered. The schematic of the freezer is shown simply in Fig. 3. The cold thermal energy storage system is a copper cube container with dimensions of $2 \mathrm{~cm} \times 28 \mathrm{~cm} \times 43.5 \mathrm{~cm}$ containing PCM. The PCM container is mounted on the roof of the freezer in the refrigeration cabin to increase free convection heat transfer. Because of the extremely nonlinear behavior and moving boundary layer during phase change process, there is a strong limitation in solving solidification and melting problem via analytical methods. It will be more complicated when two or three-dimensional analysis is required. Therefore, to solve most of the phase change problems, numerical analysis using CFD approach is a promising method. There are three well-known models proposed to solve solidification and melting phase change problems through CFD analysis: enthalpy method, equivalent heat capacity method and temperature transforming model [16].

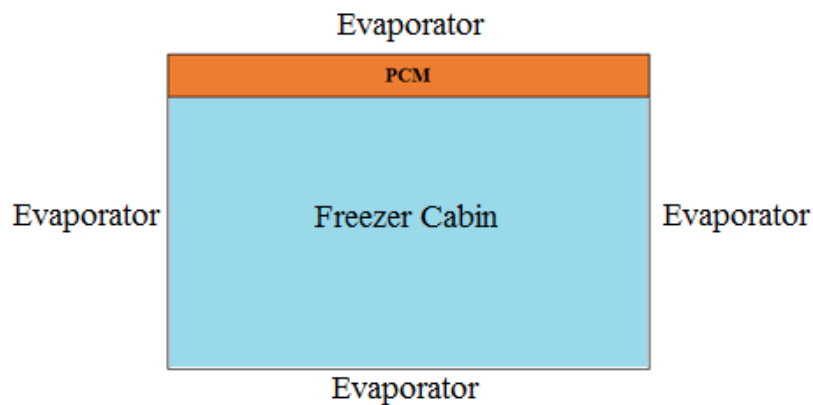

Fig. 3. The schematic view of the proposed problem Final Stage

In the present work, enthalpy method is adopted due to the one dependent variable in the transformed equation. It is supposed that the density of the liquid and solid phase are identical $\left(\rho_{\mathrm{s}}=\rho_{\mathrm{l}}\right)$. Therefore, the 2D energy equation for the internal parts and interface of PCM is as:

$\rho \frac{\partial h}{\partial t}=\frac{\partial}{\partial \mathrm{x}}\left(\frac{\mathrm{k} \partial \mathrm{T}}{\partial \mathrm{x}}\right)+\frac{\partial}{\partial \mathrm{y}}\left(\frac{\mathrm{k} \partial \mathrm{T}}{\partial \mathrm{y}}\right)$
Where $\mathrm{h}, \mathrm{k}$, and $\mathrm{T}$ are enthalpies, thermal conductivity, and temperature, respectively. Since PCM enthalpy is a function of temperature, regard with the melting temperature $\mathrm{T}_{\mathrm{m}}, \mathrm{h}(\mathrm{T})$ can be defined as:

$h(T)= \begin{cases}\mathrm{c}_{\mathrm{p}}\left(\mathrm{T}-\mathrm{T}_{\mathrm{m}}\right) & \mathrm{T}<\mathrm{T}_{\mathrm{m}} \\ \mathrm{c}_{\mathrm{p}_{\mathrm{l}}}\left(\mathrm{T}-\mathrm{T}_{\mathrm{m}}\right)+\mathrm{h}_{\mathrm{sl}} & \mathrm{T}>\mathrm{T}_{\mathrm{m}}\end{cases}$

Here, $c_{\mathrm{pl}}$ is specific heat capacity of the liquid form of PCM, and $h_{s l}$ is latent heat of PCM melting. At the PCM's melting point temperature, solid phase enthalpy and liquid phase enthalpy are 0 and $h_{s l}$, respectively. Furthermore, because of the different property of thermal conductivity coefficient in liquid and solid phase, the thermal conductivity of PCM is:

$k(T)= \begin{cases}\mathrm{k}_{\mathrm{s}} & \mathrm{T}<\mathrm{T}_{\mathrm{m}} \\ \mathrm{k}_{\mathrm{l}} & \mathrm{T}>\mathrm{T}_{\mathrm{m}}\end{cases}$

According to energy balance equation at the interface of solid and liquid of PCM in the mushy zone, the temperature can be obtained with:

$T=\left\{\begin{array}{lr}\mathrm{T}_{\mathrm{m}}+\frac{\mathrm{h}}{\mathrm{c}_{\mathrm{p}_{\mathrm{s}}}} & \mathrm{h} \leq 0 \\ \mathrm{~T}_{\mathrm{m}} & 0<\mathrm{h}<\mathrm{h}_{\mathrm{sl}} \\ \mathrm{T}_{\mathrm{m}}+\frac{\left(\mathrm{h}-\mathrm{h}_{\mathrm{sl}}\right)}{\mathrm{c}_{\mathrm{p}_{\mathrm{l}}}} & \mathrm{h} \geq \mathrm{h}_{\mathrm{sl}}\end{array}\right.$

The initial and boundary conditions for melting process is:

$$
\begin{array}{rlrl}
T(x, y, t) & =T_{i}<T_{m} & t & =0 \\
T(x, y, t) & =T_{0}>T_{m} & x, y & =0 \\
\frac{\partial T(x, t)}{\partial x} & =0 & x & =L \\
\frac{\partial T(y, t)}{\partial y}=0 & y & =L
\end{array}
$$

In $2 \mathrm{D}$ problems, the shape of the solid-liquid interface can be expressed as: $\mathrm{x}=\mathrm{s}(\mathrm{y}, \mathrm{t})$. Where $\mathrm{s}$ denotes the solid liquid interface. Two boundary conditions at the interface are as:

$$
\begin{aligned}
& \mathrm{T}_{\mathrm{l}}(\mathrm{x}, \mathrm{y}, \mathrm{t})=\mathrm{T}_{\mathrm{s}}(\mathrm{x}, \mathrm{y}, \mathrm{t})=\mathrm{T}_{\mathrm{m}} \\
& {\left[1+\left(\frac{\partial s}{\partial y}\right)^{2}\right]\left[k_{s} \frac{\partial T_{s}}{\partial x}-k_{l} \frac{\partial T_{l}}{\partial x}\right]=\rho_{l} h_{s l} \frac{\partial s}{\partial t}}
\end{aligned}
$$

The solid-liquid interface can be reconstructed in each time step in according to the Eq. (10), by applying temperature distribution. The basic model analyzed with CFD approach is a two-dimensional analysis of the freezer. In order to CFD modeling, the data of average evaporator surface temperature was acquired by direct measurement during operation of a real refrigerator, and it was $250 \mathrm{~K}$.

\section{B. Simulation and Validation}

The mentioned equations above were solved for unsteady conditions using a pressure based sequential solver. The solver employed the SIMPLE pressure velocity coupling method and the pressure were discretized using the STANDARD scheme. Solution convergence was considered 
to be reached when the velocity residuals (conservation of momentum) and continuity residuals (conservation of mass) dropped to $10^{-3}$ and energy and the discrete ordinates radiation (conservation of energy) residuals decreased to $10^{-}$ 6. To do mesh independence process the model was simulated by $8000,32000,52000$ and 72000 nodes. After all the tests, the model contained 52000 nodes was chosen as the basic model. To validate the simulation process, a model of a refrigerator and its cold thermal energy storage system which was examined by A.C. Marques [17] was considered, here. After considering all assumptions and thermophysical parameters, simulation of that experimental study was performed. Finally, numerical results were compatible with the experimental one. In the following main assumption to solve the problem are:

1- Constant thermo-physical properties for the PCM (thermal conductivity and specific heat)

2- The convection in the melted regions was neglected

3 - Super cooling effects were assumed to be non-existent

4- It was assumed that conduction was the only heat transfer mechanism inside the PCM;

The results shown in Table III proved that simulation process and assumptions are true and reliable to be utilized in the problem which is the subject of this paper.

TABLE III: VERIFICATION CONDITIONS AND RESULTS

\begin{tabular}{ccccc}
\hline \hline \multirow{3}{*}{ Models } & Ambient & Evaporator & PCM & Melting \\
& Temperature & Temperature & Thickness \\
$(\mathrm{K})$ & $(\mathrm{K})$ & $\begin{array}{c}\text { Time } \\
(\mathrm{min})\end{array}$ \\
\hline Reference & 278 & 263 & 0.005 & 243 \\
Tested & 278 & 263 & 0.005 & 240 \\
\hline \hline
\end{tabular}

\section{RESULTS}

\section{A. Thermal Simulation}

In order to understand the thermal condition of the freezer cabin during charging (solidification) and discharging (melting) of CTES system, the model of the system was simulated numerically in FLUENT 16 as the powerful CFD software. The initial temperature of the PCM was presumed at melting temperature $(252 \mathrm{~K})$. According to extracted results, the complete solidification period of PCM took 60 minutes. As can be seen in Fig. 4, at the end of the charging process, the PCM and freezer cabin average temperatures reach to 250.4 and $250.8 \mathrm{~K}$, respectively. In next step, to simulate discharging period, it was assumed that compressor had been turned off and the CTES system would prepare cold flux for the freezer's cabin. Numerical simulation continues its running until freezer cabin's temperature exceeds from standard range. According to Fig. 4, the duration of discharging period is 270 minutes. It means CTES system could keep the cabin near to the maximum standard range $(260.5 \mathrm{~K})$ [18] without using a compressor, for 4.5 hours. Numerical simulation shows that at the final point in the discharging process the PCM average temperature $(255.7 \mathrm{~K})$ is higher than its melting point temperature $(252 \mathrm{~K})$. Indeed it could be inferred that all of the PCM volumes was melted in the course of discharging process, and PCM could release its stored cold latent thermal energy into the cabin.

Regarding Fig. 4, the temperature of the PCM increases from the initial instant of discharging process until it reaches the melting point temperature. In this period, cabin temperature increases significantly because of only sensible heat is transferred from the cold PCM into the freezer cabin. However, when the PCM temperature reaches to phase change point, it releases enormous latent cold thermal energy into the freezer cabin; therefore, the cabin temperature starts to diminish, considerably. Apparently, this amount of the latent heat depends on PCM mass in the PCM box $\left(\mathrm{m} \cdot \mathrm{h}_{\mathrm{sl}}\right)$.

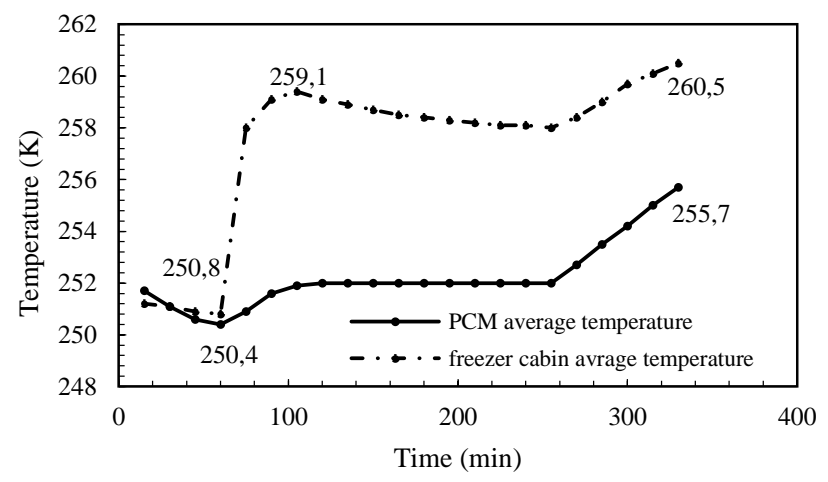

Fig. 4. Numerical result for CTES system during charging and discharging

According to Fig.s 5, PCM needs 195 minutes to melt completely (from $60^{\text {th }}$ to $255^{\text {th }}$ minutes) and during this period it can supply its stored cold thermal energy to the freezer cabin. After the melting process reaches to its final point, the cabin's temperature uses the sensible heat transfer process between the PCM slab and itself to become cold. As it is fathomed, sensible heat transfer is able to keep the cabin in the allowed range just for 75 minutes, whereas the latent heat transfer can do this for more than 195 minutes. In this way, it is proved that CTES system can keep the cabin in the allowed thermal range for 270 minutes (195 minutes by releasing latent heat and 75 minutes by transferring sensible heat capacity). This result shows that using the latent heat capacity is more effective for storing thermal energy. Indeed, materials with the high level of latent heat capacity can store a huge amount of thermal energy and release it to the aimed system in any urgent time.

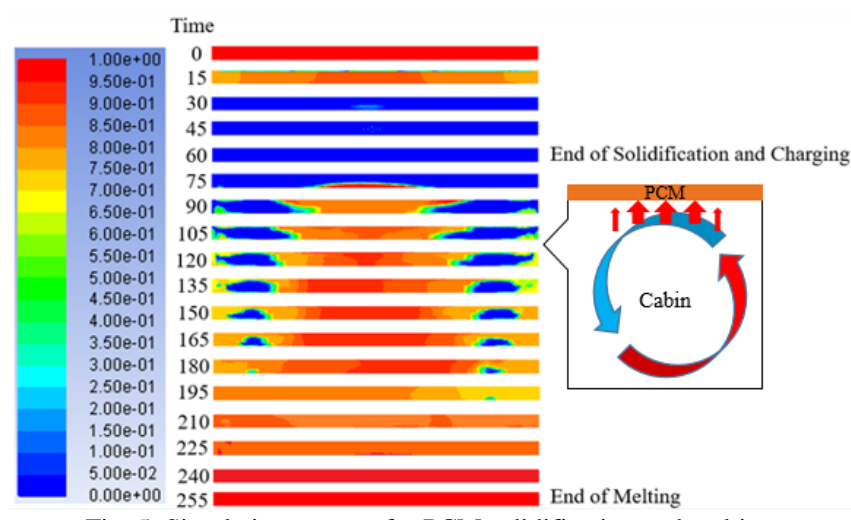

Fig. 5. Simulation process for PCM solidification and melting

Regard with the Fig. 5, by starting solidification process PCM is frozen, gradually from PCM container's roof to its floor. As it is shown, the PCM become frozen in a layer because of thermal conduction phenomenon inside of the PCM layers. After solidification, melting process will be started, immediately. It should be noted that during the melting process refrigeration system is off and thus 
evaporator surfaces work such as a thermal bridge between PCM and outside environment. As far as the main heat transfer mechanism between PCM and cabin's air during melting (discharging) is free convection, and because of the circulation of the air inside of the cabin (it derives from the differences amid the density of the warm and cold air) that is shown in Fig. 5, melting is started from the middle region of the PCM. Since the pass of the cabin's air is similar to a circle, the warm air will face the PCM surface in its middle part, firstly. By elapsing time the melting process will extend to edges of the PCM box, and after 195 minutes the PCM get all of its volumes melted.

\section{B. Energy and $\mathrm{CO}_{2}$ Emission Reduction}

One of the effective applications of CTES system is picking-off of the power distribution grid. Therefore, for a good working of this system, the releasing period of the cold thermal energy should be matched with the pick load period. In this case, the CTES system reduces not only the energy consumption but also the energy cost for consumers. In this study, the chosen freezer's power consumption is $149 \mathrm{~W}$ and compressor works 11 minutes per hour. Hence, it can be found that the compressor works for 50 minutes during 4.5 hours in the pick time (18:00 to 22:30). Fig. 6 shows simply the compressor working mode for two types of usage. It is seen that when there is no CTES system in the freezer, the compressor works periodically, however when it is equipped with CTES system, it is able to keep its compressor turned off during the pick time. Therefore, for the equipped freezer with CTES system, the compressor will be turned off for 50 minutes and energy consumption will degrade about 125 $\mathrm{Wh} /$ day, or $45.7 \mathrm{kWh} /$ year. This reduction is just for a freezer, and for millions freezer working in a country, this reduction has a high impact on total energy consumption.

Technically, when a system has a reduction in energy consumption, it would have a noticeable reduction in $\mathrm{CO}_{2}$ emission. According to the U.S. Energy Information Administration production of $1 \mathrm{kWh}$, electric energy needs to consume 0.3-liter fossil fuel (on average) and releases 0.7 $\mathrm{kg} \mathrm{CO}$ to the environment [19]. If a system is designed to reduce energy consumption, then fuel consumption and pollutions emission will decrease significantly. In Fig. 7, the comparison between the normal freezer and equipped freezer with CTES system is shown for an annual evaluation. As can be seen in Fig. 7 using CTES system prompts a perceptible reduction in energy consumption, fuel consumption and $\mathrm{CO}_{2}$ emission up to $19 \%$.

\section{CONCLUSION}

One of the effective solutions to reduce energy consumption during pick time modes is using thermal energy storage systems. Using this system not only degrades energy consumptions and its cost but also can reduce environmental emissions. Accordingly, using phase change materials, as their capability to store latent heat energy, in the storage system could be a reliable choice. In this case, as it was implied, using eutectic water-salt solution ( $\mathrm{NaCl}-$ $\mathrm{H}_{2} \mathrm{O}$ ) as its proper thermo-physical properties would be the best choice. However, as was mentioned cold thermal energy storage system equipped with phase change material was examined numerically to find out the amount of reduction in energy consumption of a household freezer during pick time. In regard to simulation process, the proposed system could keep the freezer's cabin in the standard thermal condition for 4.5 hours, without using a compressor. By turning off the compressor in this period, there will be a considerable reduction in energy consumption (45.7 kWh/year). This reduction, not only diminishes fossil fuel consumption about 13.7 liters/year, but also decreases $\mathrm{CO}_{2}$ emission from 165.5 to 135.52 $\mathrm{kg} /$ year.

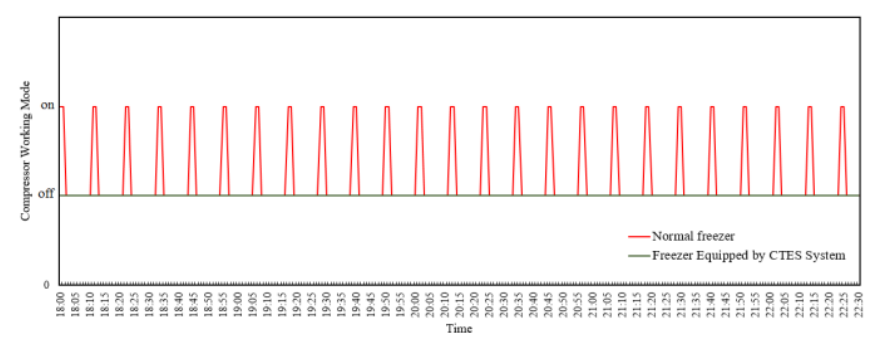

Fig. 6. Compressor working modes in normal freezer and equipped with CTES system during pick time

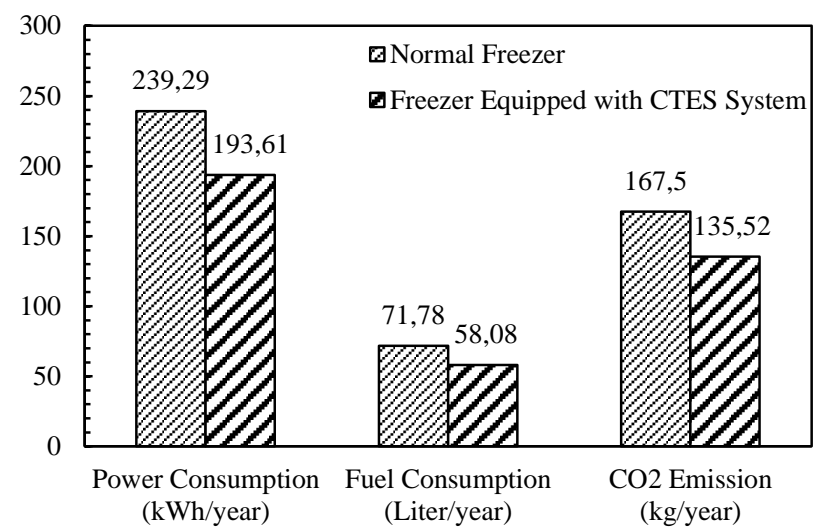

Fig. 7. Comparison amid normal freezer and equipped with CTES system for an annual evaluation

\section{REFERENCES}

[1] D. Ibrahim, MA. Rosen, Thermal energy storage, NY.: Wiley, 2002, pp. 1-479.

[2] Cool thermal energy storage, American Society of Heating, Refrigerating and Air Conditioning Engineers, ASHRAE Journal vol.48, pp. 94-96, 2003.

[3] M. MacCracken, Energy storage providing for a low-carbon future, ASHRAE, pp. 1-6, 2010.

[4] Source energy and environmental impacts of thermal energy storage, California Energy Commission, Report No. pp. 500-595, 1996.

[5] S. Morgan, M. Krarti , Impact of electricity rate structures on energy cost savings of pre-cooling controls for office buildings, Journal of Building and Environment, vol. 42, pp. 2810-2818, 2007.

[6] L.F. Cabeza, J. Roca, M. Nogués, B. Zalba, J.M. Marín, Transportation and conservation of temperature sensitive materials with phase change materials state of the art, advanced thermal energy storage techniques feasibility studies and demonstration projects, 2nd workshop, Ljubljana, Slovenia, 2002.

[7] H. Kowata, S. Sase, M. Ishii, H. Moriyama, Cold water thermal storage with phase change materials using nocturnal irradiative cooling for vegetable cooling, Proceedings of the world renewable energy congress WII. 2002.

[8] M. Mastani Joybari, F. Haghighata, J. Moffat, P. Sra, Heat and cold storage using phase change materials in domestic refrigeration systems: The state of the art review, Energy, and Buildings, vol.106, pp.111-124, 2015.

[9] A. Real, V. García, L. Domenech, J. Renau, N. Montés, F. Sánchez, Improvement of a heat pump based HVAC system with PCM thermal storage for cold accumulation and heat dissipation, Energy and Buildings, vol.83, pp.108-116, 2014.

[10] A.C. Marques, G.F. Davies, G.G. Maidment, J.A. Evans, I.D. Wood, Theoretical Modelling and Experimental Investigation of a Thermal 
Energy Storage Refrigerator, Journal of Energy, vol.55, pp.457-465, 2013.

[11] B. Rismanchi, R. Saidur, H.H. Masjuki, T.M.I. Mahlia, Modeling, and simulation to determine the potential energy savings by implementing cold thermal energy storage system in office buildings, Energy Conversion and Management, vol. 75, pp. 152-161, 2013.

[12] K. Azzouz, D. Leducq, D. Gobin, Enhancing the Performance of Household Refrigerators with Latent Heat Storage an Experimental Investigation, International Journal of Refrigeration, vol. 32, pp. 1634 $-1644,2009$.

[13] . Azzouz, D. Leducq, D. Gobin, Performance Enhancement of a Household Refrigerator by Addition of Latent Heat Storage, International Journal of Refrigeration, vol. 31, pp. 892-901, 2007.

[14] H. Mehling, L.F. Cabeza, Heat, and Mass Transfer: Heat and Cold Storage with PCM, Springer, Berlin, pp.1-177, 2008.

[15] G. Li, Y. Hwang, R. Radermacher, H.H. Chun, Review of Cold Storage Materials for Sub-Zero Applications, Journal of Energy, vol. 51, pp. 1-17, 2013

[16] A. Faghri, Y. Zhang, Transport Phenomena in Multiphase Systems, UK: Academic Press London, 2006, pp. 421-499.

[17] A.C. Marques, G.F. Davies, G.G. Maidment, J.A. Evans, I.D. Wood, Novel Design and Performance Enhancement of Domestic Refrigerators with Thermal Storage, Applied Thermal Engineering, vol. 63, pp. 511-519, 2013.

[18] Refrigerating and Air-conditioning Engineers, American Society of Heating, ASHRAE Refrigeration Handbook, Atlanta, 2010, pp. 147158.

[19] U.S. Energy Information Administration (Online) Available:http://www.eia.gov.

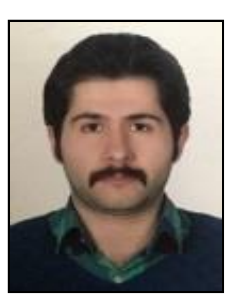

Omid Ghahramani Zarajabad was born in 1988, Islamic Republic of Iran. He has graduated with an M.Sc. in Energy Systems Engineering in the field of energy and environment from Iran University of Science and Technology (IUST) in 2016. Also, he has B.Sc. in mechanical engineering in the field of heat transfer.

His main research issue is using phase change materials in the thermal energy storage systems.
To achieve this aim he has worked on heat and thermal systems since 2013. Besides, he has a proper experience in the field of solar and wind systems from 2014. Moreover, his research interests are finding reliable solutions to reduce energy consumption and environmental pollution. Recently, he is working on high-temperature PCMs to use in solar thermal systems to store thermal energy.

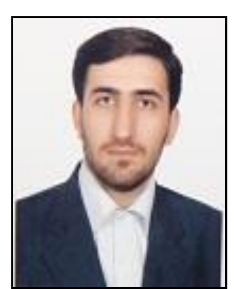

Rouhollah Ahmadi was born in the Islamic Republic of Iran. He has graduated with a Ph.D. in Mechanical Engineering from Osaka University, Japan in 2013. Also, he has graduated with an M.Sc. and B.Sc. from the Sharif University of Technology in Mechanical Engineering. From 2013 he has been working as an assistant professor of the Iran University of Science and Technology in the field of Energy Systems Engineering.

His main research interests are using phase change materials in the thermal energy storage systems, optimizing the existing energy systems, using Nano- fluids to improve heat transfer phenomena, investigation of multiphase flow and boiling heat transfer and development of the solar thermal system by considering thermal energy storage process. In the field of his interests, he has published 12 journal's papers and 18 international conferences' papers. Also, he has supervised more than 25 master thesis in the field of energy systems engineering.

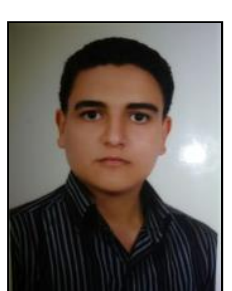

Saeed Ghaffari was born in 1991, Islamic Republic of Iran. He has graduated with an M.Sc. in Mechanical Engineering in the field of energy conversion from Mazandaran University of Science and Technology in 2017. Also, he has B.Sc. in mechanical engineering in the field of fluid and heat transfer.

His main research contains improvement of the thermal energy storage systems. In regard to his research, he has investigated using fins inside of the PCMs to ameliorate their conductivity. Also, he is working on high-temperature PCMs to use in solar thermal systems. 